\title{
Extraction of Green Acid-Base Indicators From Acanthus Pubescens Flower for Use in the School Laboratory
}

\author{
Sintayehu Leshe ${ }^{1}$, Habitamu Baye ${ }^{1}$ \\ ${ }^{1}$ Debre Markos University, College of Natural and Computational Sciences, Department of Chemistry, Ethiopia \\ Correspondence: Debre Markos University, College of Natural and Computational Sciences, Department of Chemistry, \\ Ethiopia.
}

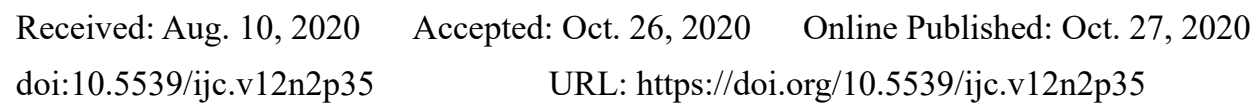

\begin{abstract}
The use of Acanthus pubescens flower extracts as natural eco-friendly substitutes for synthetic acid - base indicators is experimentally confirmed. In this study, it is indicated that ethanolic and acidified ethanol extracts of Acanthus pubescens flower are good replacements to phenolphthalein, bromothymol blue and methyl red in acid-base titrations involving a strong acid versus strong base and a strong acid versus weak base. They can also be used as effective substitutes to phenolphthalein in a weak acid versus strong base titrations. And also the acidified ethanol extracts can be used in place of phenolphthalein and bromothymol blue while the ethanol extracts can replace methyl red in weak acid versus weak base titrations. It is also concluded that the use of Acanthus pubescens flower extract as an indicator in all types of acid base titrations is beneficial because of its economy, eco-friendly nature, ease of preparation, availability, simplicity, non-carcinogenicity, precision and accuracy of results.
\end{abstract}

Keywords: Acanthus pubescens flower; acidified ethanol; natural indicator; anthocyanins, flavonoids

\section{Introduction}

Natural acid-base indicators are greener alternatives to synthetic ones as they are the demand of contemporary chemistry with regards to solving the problems of environmental pollution, cost and human health. There is an increasing need for the development of green indicators as effective substitutes for synthetic acid-base indicators used in the school chemistry laboratory.

A change in colour during acid-base titrations with variation in $\mathrm{pH}$ is due to presence of coloured pigments that are used in acid base titrations to show sharp end point (Mane et al., 2016). Commonly used indicators for such titrations are manmade and costly. Besides, some of them have toxic effects on users and can also cause environmental pollution. For these and other reasons, there have been increasing concerns in searching for greener sources of acid-base indicators. These greener and eco-friendly alternatives would be cheaper, more available, simple to extract, less toxic to users and environmentally viable (Abugri et al., 2012). Some highly coloured pigments obtained from plants are found to exhibit colour changes at various $\mathrm{pH}$ values (Mane et al., 2016). In the Present study, we prepared ethanolic and acidified ethanol Acanthus pubescens flower extract as a natural indicator for acid-base titration.

Acanthus pubescens belongs to the family of Acanthaceae. It is used in traditional medicine for treatment of syphilis and gonnorhea. A decoction of the leaves is used for the treatment of gastroenteritis, pneumonia and anthrax. It is also reported that, a preparation of the dried leaves is used externally as a remedy for scabies (Moshi et al., 2010). The leaves are burned to ash and licked to treat cold, cough, liver problem, chronic asthma, cancer, tonsils and flu (Seswa, 2016; Jeruto et al., 2008). The leaves of Acanthus pubescens contain various classes of compounds such as flavonoids, terpenes, alkaloids and saponins identified through phytochemical screening test, which might be responsible for the traditional use of the plant (Sikolia et al., 2017) where it is hypothesized that pH indicators can possibly be produced from Acanthus pubescens plants because of flavonoids which are $\mathrm{pH}$ sensitive.

Many experiments have been carried out on the use of plant pigment extracts as green substitutes to synthetic acid-base indicators. Flower extracts of Jacaranda Acutifolia were used as indicator in acid-base titrations (Patrakar et al., 2010) in which the equivalence point obtained by the flower extracts coincided with the equivalence point obtained by synthetic ones. In case of weak acid and weak base titration, the results obtained by the flower extract matched with the results obtained by mixed indicator. Gaurav et al (2010) studied the extracts of Bougainvillea glabra flowers changing colour in aqueous solutions of acids and bases. The researchers compared the results of the Bougainvillea glabra 
flowers extracts with phenolphthalein and methyl orange in acid-base titrations as indicator. The results indicated that the extract obtained from flowers of Bougainvillea glabra could be used as indicators for strong acid vs. strong base titrations as similar results were obtained by phenolphthalein. On the other hand, methanolic extracts of the leaves of careya arborea were also used as indicators in acid base titrations (Wadkar et al., 2008). Promising results were obtained when a natural indicator prepared from methanolic extracts of the species were tested against standard synthetic indicators. The indicator was useful in all types of acid - base titrations except weak acid and weak base titration. Okonkwo et al., (2010) used Hibiscus Sabdariffa petals extract for acid - base titrations. The results were compared with those of standard end point indicators as phenolphthalein and methyl red. Prominent absorption peaks in the $500-550 \mathrm{~nm}$ wavelength region of the UV/Visible spectrum of methanolic extract confirmed the presence of anthocyanidins. In other studies, methanolic extracts of Antirrhinum majus belonging to the family of Scrophulariaceae as well as Dianthus plumaris which belong to the family of Caryophyllaceae were used which gave sharp and intense colour change as compared to phenolphthalein and methyl orange indicators (Jaspreet et al., 2011). In all these titrations the extract was found to be accurate and useful for indicating the end point of a neutralization reaction.

Colour changes of natural indicators at different $\mathrm{pH}$ values have been attributed to the presence of anthocyanins and flavonoids which are $\mathrm{pH}$ sensitive. Anthocyanins are organic compounds that are usually found in the aqueous sap of the vacuole of the epidermal plant cells. These compounds have a complex structure consisting of an aromatic three-ring molecular structure, one or more attached sugar molecules and sometimes acyl groups attached to the sugar molecules. Anthocyanins are water soluble and are usually more stable in acidic media than in alkaline solutions. A general structure of an anthocyanin is shown in Figure 1.

Almost any plants that have blue, violet, purple or red flowered colours contain organic pigments, anthocyanins that changes colour with change in $\mathrm{pH}$. The colour stability of anthocyanins depends on structure of the anthocyanins, $\mathrm{pH}$, temperature, oxygen, and light and water activity. They tend to be red in a more acidic solution and blue in basic solution (Nhapi, 2016).

Anthocyanins have several physiological activities which include antioxidant, anti-hepatocarcinogenic, anti-inflammatory, anti-tumour, hypolidemic, cardioprotective and cancer chemopreventive, hence they are safe to use in acid-base titration.

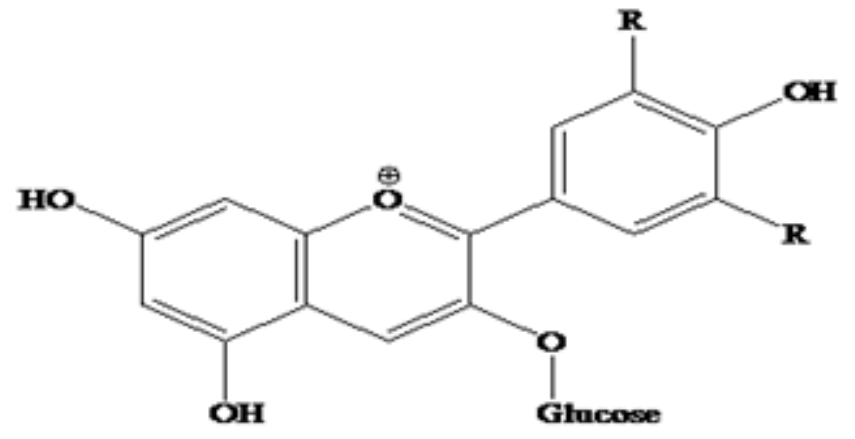

Figure 1. General structure of anthocyanin (Nhapi, 2016)

\section{1 pH Dependant Structural Transformations of Anthocyanins}

Due the high reversibility of the various forms of cyanidins in aqueous solutions, different colours are observed with respect to changes in $\mathrm{pH}$. At acidic $\mathrm{pH}$ (1-3), as shown in Figure 2, anthocyanins exist predominantly in the form of the red or orange flavylium cation (2-phenylchromenylium cation). The colour intensity decrease as $\mathrm{pH}$ increases and also the concentration of the flavylium cation decreases which undergoes hydration to produce the colourless pseudo base (hemiacetal or chromenol). This is due to kinetic and thermodynamic competition between hydration reaction of the flavylium cation and proton transfer reactions related to the acidic hydroxyl groups of the aglycone. The conjugated 2-benzopyrilium system is disrupted due to a nucleophilic attack of water at position 2 of the anthocyanidin skeleton. Flavylium cation lose proton as the $\mathrm{pH}$ shifts higher. The equilibrium will now shift towards a purple quinoidal anyhydrobase at $\mathrm{pH}<7$ and a deep blue ionised anhydrobase at $\mathrm{pH}<8$. As the $\mathrm{pH}$ increases further, the carbinol form yields through opening of the central pyran ring and the light yellow chalcone will result. The anthocyanidin system undergoes a variety of molecular transformations as $\mathrm{pH}$ changes, thus in aqueous solutions, anthocyanidins exist as five molecular species in chemical equilibrium which are red flavylium cation, colourless carbinol pseudo base, purple quinoidal base, blue quinoidal base anion and yellowish chalcone. These transformations are shown by the mechanism 
shown on Figure 2. Plant species containing anthocyanins can change colour in solution by undergoing these transformations due to change in the acidity or basicity of the solution (Nhapi, 2016).<smiles>OC1=Cc2c(O)cc(O)cc2O[C@@H]1c1ccc(O)c(O)c1</smiles>

2-(3.4-dihydruxypheng1)-3.5.7-mikydury-2H-dnomengtium Finyine ontin FH 53 rad

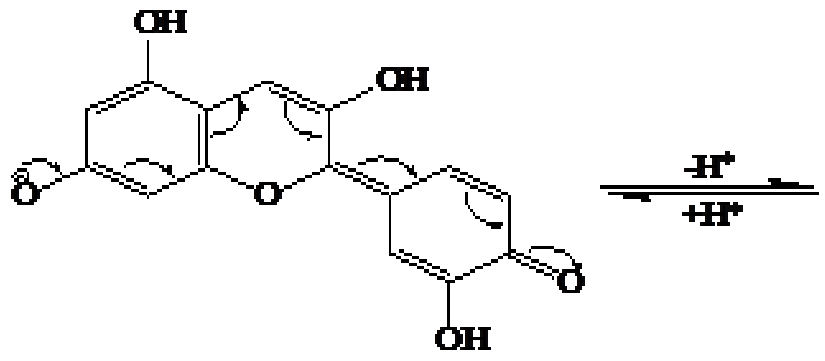

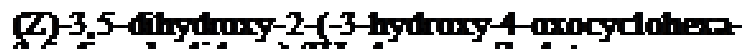
25-dien-1-yidene)-2H-diumen-7-dite

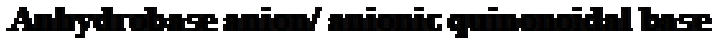
pH=7-8 the<smiles>CC(C)C(C)C(C)(C)C</smiles><smiles>O=C(/C(O)=C\c1c(O)cc(O)cc1O)c1ccc(O)c(O)c1</smiles><smiles>OC1=Cc2c(O)cc(O)cc2CC1(O)c1ccc(O)c(O)c1</smiles>

2-(3,4-6hyiturytheng)-2H-dhomene2,35.7-nenat

Cabinal ps: ndibere PH $=45$ olmales<smiles>O=C1C=CC(=C2Oc3cc(O)cc(O)c3C=C2O)C(O)=C1O</smiles>

(Z)-2-hylumg-4-3.5.7-tilhyitury-3Hchimen-2-yidene)cydothen-2,5-dienne

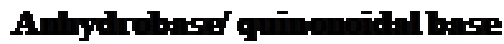
$\mathbf{P H}=\mathbf{6 - 7 v i \mathbf { m }}$

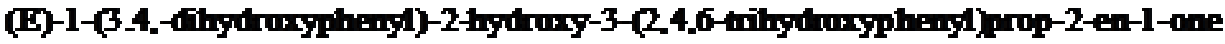

\section{Cheline}

PH> 8y: yer

Figure 2. Structure of Cyanidins in aqueous solution under varying $\mathrm{pH}$ (Nhapi, 2016)

\subsection{Research Questions}

In this study, we successfully prepared a natural, eco-friendly, cheaper and locally available acid-base indicator from Acanthus pubescens flower extracts. We have specifically given answers the following questions:

1. What are the characteristics of the active components that give the acid-base indicator properties of Acanthus pubescens flower extracts?

2. What are the resulting colours of Acanthus pubescens flower extracts in the $\mathrm{pH}$ range of 1 to 14

3. are there any significant differences between the results of the extracted $\mathrm{pH}$ indicator with phenolphthalein, bromothymol blue and methyl red $\mathrm{pH}$ indicators in determining the end point in different types of acid-base titration? 


\section{Materials and Methods}

\subsection{Reagents, Apparatus and Equipments}

The principal raw material used for the study was the powdered Acanthus pubescens flower. All reagents used in the practical work were of analytical grade and used without further purification. These include hydrochloric acid $(\mathrm{HCl}$, 35-36\%, UNI-CHEM Chemical Reagents, India), sodium hydroxide (NaOH, 98\%, BLULUXR Analytical Reagents), glacial acetic acid $\left(\mathrm{CH}_{3} \mathrm{COOH}, 99.5 \%\right.$, SCR-China), ammonia $\left(\mathrm{NH}_{3}, 30 \%\right.$, Merch, Germany), borax $\left(\mathrm{Na}_{2} \mathrm{~B}_{4} \mathrm{O}_{7} .10 \mathrm{H}_{2} \mathrm{O}\right.$, 99.0 - 103\%, SAMIR TECH-CHEM PVT, LTD), iron (III) chloride $\left(\mathrm{FeCl}_{3}, 99.0 \%\right.$, Avi Chem Industries, India), magnesium ribbon (Mg, BUCK SCIENTIFIC PURO-GRAPHIC), zinc dust (Zn, BUCK SCIENTIFIC PURO-GRAPHIC), ethanol $\left(\mathrm{CH}_{3} \mathrm{CH}_{2} \mathrm{OH}, 97 \%\right.$, Fine Chemical General Trading, Ethiopia) and distilled water. The commercial indicators were phenolphthalein $\left(\mathrm{C}_{20} \mathrm{H}_{14} \mathrm{O}_{4}\right.$, SAMIR TECH-CHEM PVT, LTD), methyl red $\left(\mathrm{C}_{15} \mathrm{H}_{15} \mathrm{~N}_{3} \mathrm{O}_{2}\right.$, SAMIR TECH-CHEM PVT, LTD), bromothymol blue $\left(\mathrm{C}_{27} \mathrm{H}_{28} \mathrm{Br}_{2} \mathrm{O}_{5} \mathrm{~S}\right.$, SAMIR TECH-CHEM PVT, LTD). The instruments that were used in the study are $\mathrm{pH}$ meter (Elmetron CPI-501, Poland), double beam UV-Vis spectrophotometer (6705, Jenway), electronic analytical balance (AA200DS, Deriver Instrument Company, Germany) and magnetic stirrer (MS300, Germany). The following apparatus and equipments such as Erlenmeyer flasks, volumetric flasks, burette with volume size of $50 \mathrm{~mL}$, micropipette $(1-10 \mu \mathrm{L}, 10-100 \mu \mathrm{L}$ and $100-1000 \mu \mathrm{L})$, test tubes, beakers, graduated measuring cylinders with volume size of $10 \mathrm{~mL}$ and $25 \mathrm{~mL}$, and Whatman filter paper No. 41 were used to carried out the experiment. All required reagents and volumetric solutions were prepared as per standard.

\subsection{Collection and Preparation of the Acanthus Pubescens Flower}

One kilogram of fresh Acanthus pubescens flower were collected from around Debre Markos, Ethiopia, at the beginning of December 2019, as it is the blooming season of the plant. The fresh flower petals of Acanthus pubescens were separated from the whole flower by hand and washed with distilled water to remove dirt. The fresh Acanthus pubescens flower petals were air dried for three weeks without exposure to direct sunlight to minimize oxidative loss before pounding in to fine powder at room temperature. The dried flower petals were ground into fine powder, as shown in Figure 3 below, with coffee grinding machine and the powders were sieved and stored in a polyethylene bag before use.
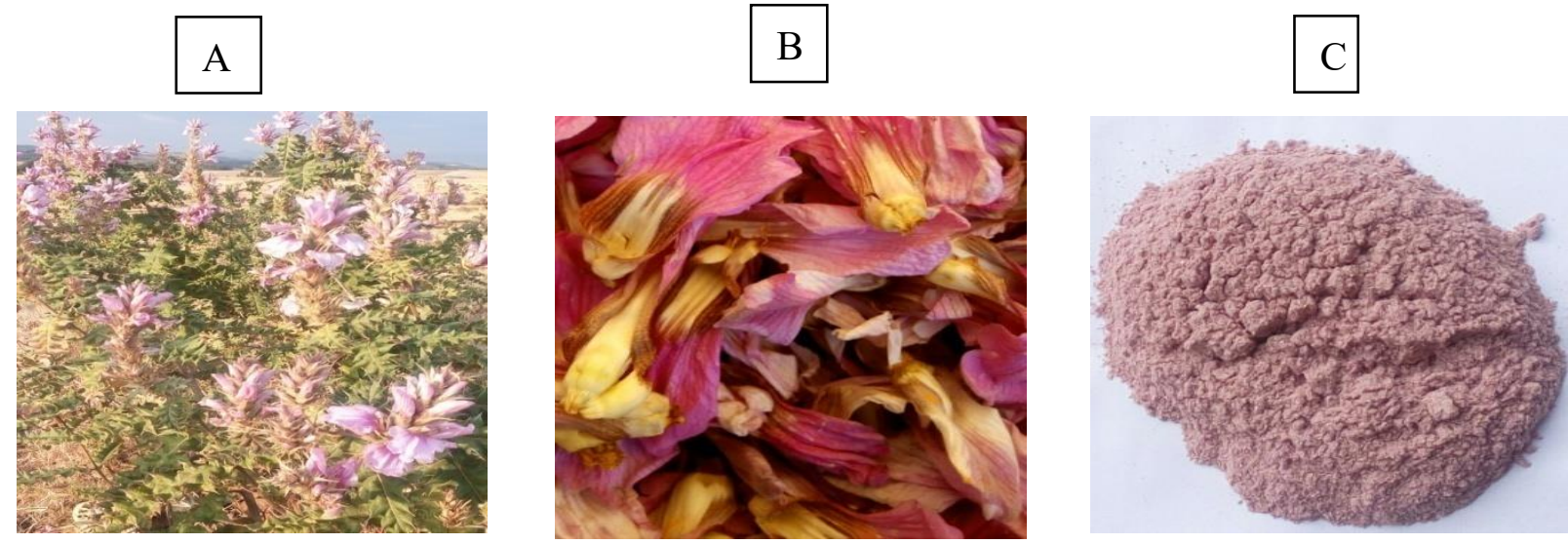

Figure 3. Acanthus pubescens flower (A), dried and powdered samples (B \& C)

\subsection{Extraction of the Indicator}

30 grams of dried powder of Acanthus pubescens flower was mixed with $150 \mathrm{~mL}$ of $97 \%$ ethanol in 250 milliliter Erlenmeyer flask and then the mixture was stirred by using a magnetic stirrer for 2 hours to disperse the powder completely (Figure 4). The mixture was kept at room temperature for 24 hours and then triturated in mortal and pestle and the resulting solution were filtered by using Whatman filter paper to remove the remaining plant matter. Similar procedures were applied by taking the same amount of powder and solvent for all the rest extracting solutions. The resulting $97 \%$ ethanol and $0.1 \% \mathrm{HCl}$ in ethanol extract were further used as natural $\mathrm{pH}$ indicator for acidimetry and alkalimetry. The extract was preserved in light closed container and stored away from direct sunlight to prevent photolysis and decomposition (Nhapi, 2016; Gupta et al., 2013). 


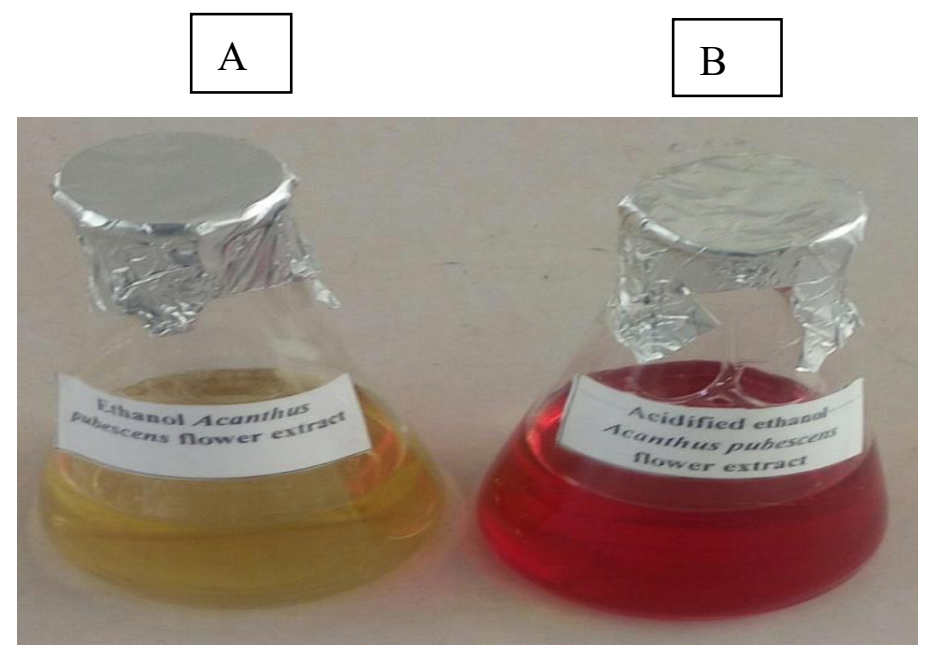

Figure 4. Colours of extracted solutions of Acanthus pubescens flower in ethanol (A) and acidified ethanol (B) 2.4 UV-Vis Spectroscopy Analysis

The UV-Vis absorption spectra of ethanol and acidified ethanol extracts of Acanthus pubescens flower were determined using UV-Vis spectrophotometer (6705, Jenway) in the wavelength range of $200 \mathrm{~nm}$ to $800 \mathrm{~nm}$. The extracted solutions were diluted by a factor of 10 with the same solvent and $5 \mathrm{~mL}$ of the extract was measured and placed in the quartz cuvette. The wavelength of maximum absorption of each extract was determined and the compounds present in the extracts were interpreted.

\subsection{Phytochemical Screening of the Extracts}

The extracts were phytochemically screened in order to determine the presence/absence of flavonoids and anthocyanins in the flowers of the Acanthus pubescens plant extracts. Alkaline reagent test, Shinoda's test, hydrochloric acid test, zinc test (Loganathan et al., 2017) and ferric chloride test (Shah, 2016) were used for the presence of flavonoids. On the other hand, the presence of anthocyanins was tested by adding $2 \mathrm{~mL}$ of the plant extract in $2 \mathrm{~mL}$ of $2 \mathrm{M} \mathrm{HCl}$. The appearance of a pink-red colour that turns purplish blue after addition of ammonia indicates the presence of anthocyanins (Obouayeba et al., 2015)

\subsection{Titration Using Acanthus Pubescens Flower Extract, Methyl Red, Bromothymol Blue and Phenolphthalein Indicators}

Obtaining equivalence point in different types of titration of the Acanthus pubescens flower extracts in comparison with synthetic indicators was tested. Four titrations were performed i.e. strong acid versus strong base, strong acid versus weak base, weak acid versus strong base and weak acid versus weak base. The titrations were conducted in the order $\mathrm{HCl}$ and $\mathrm{NaOH} ; \mathrm{HCl}$ and $\mathrm{NH}_{4} \mathrm{OH} ; \mathrm{CH}_{3} \mathrm{COOH}$ and $\mathrm{NaOH}$ and $\mathrm{CH}_{3} \mathrm{COOH}$ and $\mathrm{NH}_{4} \mathrm{OH}$. A volume of $10 \mathrm{~mL}$ of $1 \mathrm{M} \mathrm{HCl}$ was placed in an Erlenmeyer flask and four drops of Acanthus pubescens flower extract indicator were added while $1 \mathrm{M}$ $\mathrm{NaOH}$ was placed in a burette. The titrant $(\mathrm{NaOH})$ was added to titrate $(\mathrm{HCl})$ until a colour change was observed. Titrations were conducted in three replicate analyses. The procedure was repeated for all titrations i.e. $\mathrm{HCl}$ versus $\mathrm{NH}_{4} \mathrm{OH}, \mathrm{CH}_{3} \mathrm{COOH}$ versus $\mathrm{NaOH}$ and $\mathrm{CH}_{3} \mathrm{COOH}$ versus $\mathrm{NH}_{4} \mathrm{OH}$.

Equimolar titrations were performed using $10 \mathrm{~mL}$ of titrant with four drops of indicator. A set of three experiments each for all the types of acid base titrations was carried out by using $1 \mathrm{M}$ solution of acid and base. The mean and standard deviation for each type of acid base titrations were calculated and recorded as mean \pm standard deviation.

\section{Results and Discussion}

\subsection{UV-Vis Spectroscopy Analysis of the Acanthus Pubescens Flower Extracts}

UV-Vis spectrophotometric analysis was performed on ethanolic and acidified ethanol extracts of Acanthus pubescens flower. The wavelength regions of the spectral absorbance peaks are used to identify the the active components present in the plant species. The UV-Vis absorption spectra for the dye solution extracted using the ethanolic and acidified ethanol are shown in Figures 5 below. As shown in the figures, the extracted solutions have shown absorption peaks at $224 \mathrm{~nm}, 267 \mathrm{~nm}, 331 \mathrm{~nm}$ and $524 \mathrm{~nm}$ in ethanolic extract. These absorption peaks of the extracted dye are closely related to flavonoids and anthocyanin as reported by other investigators (Obaseki et al., 2017; Nuryanti et al., 2013; Wuletaw et al., 2016). The UV-Vis absorption spectra of flavonoids consist of two distinctive bands in a broad range of $240-550$ $\mathrm{nm}$. Band I, covering the range $300-550 \mathrm{~nm}$, while band II, covering the range of $240-285 \mathrm{~nm}$ (Obaseki et al., 2017). 
Anthocyanin can be readily distinguished from other flavonoid classes by performing colour test and UV-Vis analysis $\left(\lambda_{\max }\right)$. Anthocyanins generally have two absorption maxima, one in the UV-region of spectrum $260-280 \mathrm{~nm}$ (band II) and the second in the visible region of spectrum $490-550 \mathrm{~nm}$ (band I) (Ahmed et al., 2013). Almost all flavonoid classes give the same absorption at the region of band II, thus, anthocyanins can be distinguished from other classes by observing the absorption region wavelength of band I (Nuryanti et al., 2013).

Figures 5 (A) and 5 (B) show the UV-Vis absorption spectra of dye solutions of Acanthus pubescens flower extracted using ethanol and acidified ethanol. All the extracted solutions show a UV-Vis absorption peak in the UV-Vis region of the spectrum at $224 \mathrm{~nm}, 267 \mathrm{~nm}, 331$ and $524 \mathrm{~nm}$ for ethanol extracts of Acanthus pubescens flower; and $224 \mathrm{~nm}, 275 \mathrm{~nm}$, $331 \mathrm{~nm}$ and $526 \mathrm{~nm}$ for acidified ethanol extracts of Acanthus pubescens flower. As shown in Figures 5A and 5B below, these absorption regions are also the main characteristics of flavonoid and anthocyanin pigments (Obaseki et al., 2017; Nuryanti et al., 2013; Khoddami et al., 2013).
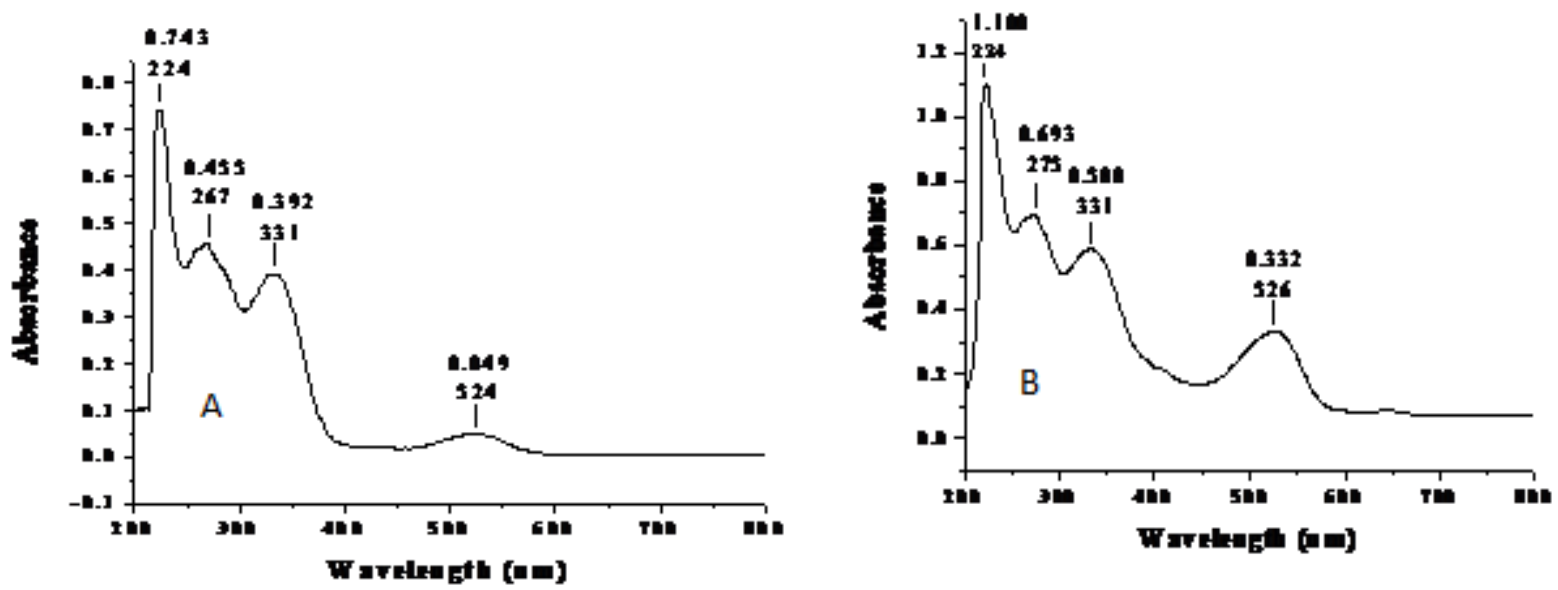

Figure 5. UV-Vis spectrum of ethanolic (A) and acidified ethanol (B) extract of Acanthus pubescens flower

\subsection{Phytochemical Screening Test of the Acanthus Pubescens Flower Extracts}

The preliminary phytochemical investigation and qualitative chemical tests of the ethanol and acidified ethanol extracts of Acanthus pubescens flower were performed using alkaline reagent test, hydrochloric acid test, ferric chloride test, zinc test, and Shinoda test which confirmed the presence of flavonoids and anthocyanin as reported in Table 1 below.

Table 1. Results of phytochemical screening of ethanol and acidified ethanol extracts of Acanthus pubescens flower

\begin{tabular}{|c|c|c|c|c|}
\hline Phytochemicals & Test & Observation & Ethanolic extract & $\begin{array}{l}\text { Acidified ethanolic } \\
\text { extract }\end{array}$ \\
\hline \multirow[t]{5}{*}{ Flavonoids } & Alkaline reagent test & Yellow & + & + \\
\hline & Ferric chloride test & greenish-black & + & + \\
\hline & Hydrochloric acid test & Red & + & + \\
\hline & Shinoda test & Red & + & + \\
\hline & Zinc test & red & + & + \\
\hline Anthocyanins & Hydrochloric acid test & Purplish blue & + & + \\
\hline
\end{tabular}

+ indicates test is positive

Different studies conducted on phytochemical tests on leaves, root and flower extracts of various plant species gave similar results (Etagegnehu et al., 2016; Sikolia et al., 2017; Singh et al., 2011). The presence of pH sensitive flavonoids and anthocyanins, as confirmed by the chemical tests and UV-Vis spectra make Acanthus pubescens flower extracts ideal indicators in acid-base titrimetric analysis.

\subsection{Colours of Acanthus Pubescens Flower Extracts in a Solution of pH 1 - 14}

The colour change interval of Acanthus pubescens flower extracts were also determined by preparing solutions having $\mathrm{pH}$ in the range of 1 to 14 and adding four drops of Acanthus pubescens flower extracts to each test tube. It is shown that in the $\mathrm{pH}$ range of 1- 7, ethanol and acidified ethanol Acanthus pubescens imparts pink colour while in the $\mathrm{pH}$ 
range of 8-11, it produces a colourless solution in all extracts, and at $\mathrm{pH} 12$ it shows a greenish yellow colour. At pH 13 and 14, a greenish yellow colour were observed in all extracts to the solution as shown in Table 2 below.

Table 2. Colour change results after addition of ethanol and acidified ethanol Acanthus pubescens flower extract in a solutions of $\mathrm{pH} 1-14$

\begin{tabular}{|c|c|c|c|c|c|c|c|c|c|c|c|c|c|c|}
\hline pH & 1 & 2 & 3 & 4 & 5 & 6 & 7 & 8 & 9 & 10 & 11 & 12 & 13 & 14 \\
\hline$\frac{\Xi}{\grave{\theta}}$ & $\stackrel{y}{\Xi}$ & $\stackrel{y}{\Xi}$ & $\underset{\Xi}{\Xi}$ & $\stackrel{y}{\Xi}$ & $\begin{array}{l}\tilde{a} \\
\vdots\end{array}$ & $\underline{a}$ & 光 & 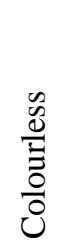 & $\frac{\tilde{d}}{\frac{0}{3}}$ & $\frac{\frac{\tilde{d}}{0}}{\frac{0}{3}}$ & $\frac{\tilde{v}}{\frac{0}{\Xi}}$ & 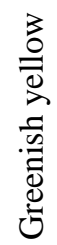 & 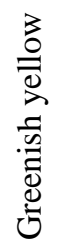 & $\begin{array}{l}3 \\
0 \\
0 \\
0 \\
\frac{0}{0} \\
0 \\
0 \\
0 \\
0\end{array}$ \\
\hline
\end{tabular}

The sensitivity of the extracts to different $\mathrm{pH}$ are attributed to the presence of flavonoids and anthocyanins. As described by Oswald's ionic theory of indicators (Kolthoff, 1937; Said, 2017), the differences in colour changes brought by the Acanthus pubescens flower extracts when subjected to different $\mathrm{pH}$ may be due to protonation or deprotonation of the Acanthus pubescens flower extracts. The colour change might be due to intramolecular rearrangement as shown in Figure 2 that causes absorptions in the different region of the UV-Vis spectrum (Ekpo, 2007). The colour changes reported in literature for other plants extracts are from dark pink to yellow whilst in this study; it is from pink to greenish yellow for the Acanthus pubescens flower extract. This might be attributed to different plant extracts being used in the other studies (Senathirajah et al., 2017) and also the crude extract component matrix might be different between the plant extracts.

3.4 Acid-Base Titration Using Acanthus Pubescens Flower Extract, Phenolphthalein, Bromothymol Blue and Methyl Red as Indicators

In order to evaluate the potential for the use of Acanthus pubescens flower extract as indicators in acid-base titrimetry, a number of titrations using the ethanol and acidified ethanol extracts were conducted. The end points of the titrations using four drops of Acanthus pubescens flower extract are reported in Table 3 . The end points of the acid-base titrations using commercially available indicators are also reported in the table.

The results in the table showed that the end points obtained with the ethanol and acidified ethanol extracts of Acanthus pubescens flower in $1 \mathrm{M}$ solutions of hydrochloric acid and sodium hydroxide (i.e. strong acid versus strong base) gave similar end points ranging from $9.73 \pm 0.058$ to $9.77 \pm 0.115 \mathrm{~mL}$ which were close to the end points obtained using phenolphthalein $(9.80 \pm 0.100 \mathrm{~mL})$, bromothymol blue $(9.77 \pm 0.115 \mathrm{~mL})$ and methyl red $(9.70 \pm 0.100 \mathrm{~mL})$ and so the Acanthus pubescens flower extract can be used in place of phenolphthalein, bromothymol blue and methyl red in acid-base titrations involving a strong acid versus strong base combination. 
Table 3. Mean volume of base used (in $\mathrm{mL}$ ) at end points and colour change for the four titrations using Acanthus pubescens flower extract, phenolphthalein, bromothymol blue and methyl red as indicators

\begin{tabular}{|c|c|c|c|}
\hline Titration & Indicators & Mean \pm Sd $^{*}$ & Colour change \\
\hline \multirow{5}{*}{ 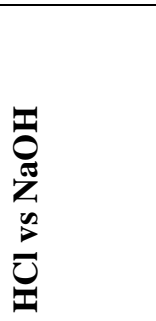 } & Methyl red & $9.70 \pm 0.100$ & Red to yellow \\
\hline & Bromothymol blue & $9.77 \pm 0.115$ & Yellow to blue \\
\hline & Phenolphthalein & $9.80 \pm 0.100$ & Colourless to pink \\
\hline & Ethanol Acanthus pubescens flower extract & $9.73 \pm 0.058$ & Pink to colourless \\
\hline & $\begin{array}{l}\text { Acidified ethanol Acanthus pubescens flower } \\
\text { extract }\end{array}$ & $9.77 \pm 0.115$ & Pink to colourless \\
\hline \multirow{5}{*}{ 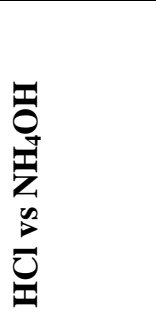 } & Methyl red & $11.20 \pm 0.200$ & Red to yellow \\
\hline & Bromothymol blue & $11.30 \pm 0.100$ & Yellow to blue \\
\hline & Phenolphthalein & $11.40 \pm 0.173$ & Colourless to pink \\
\hline & Ethanol Acanthus pubescens flower extract & $11.33 \pm 0.058$ & Pink to colourless \\
\hline & $\begin{array}{l}\text { Acidified ethanol Acanthus pubescens flower } \\
\text { extract }\end{array}$ & $11.33 \pm 0.058$ & Pink to colourless \\
\hline \multirow{5}{*}{ 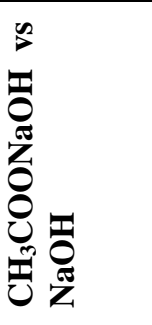 } & Methyl red & $9.53 \pm 0.058$ & Red to yellow \\
\hline & Bromothymol blue & $9.67 \pm 0.058$ & Yellow to blue \\
\hline & Phenolphthalein & $10.40 \pm 0.100$ & Colourless to pink \\
\hline & Ethanol Acanthus pubescens flower extract & $10.43 \pm 0.058$ & Pink to colourless \\
\hline & $\begin{array}{l}\text { Acidified ethanol Acanthus pubescens flower } \\
\text { extract }\end{array}$ & $10.40 \pm 0.100$ & Pink to colourless \\
\hline \multirow[t]{2}{*}{ 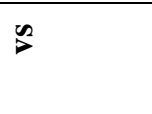 } & Methyl red & $8.07 \pm 0.115$ & Red to yellow \\
\hline & Bromothymol blue & $8.77 \pm 0.208$ & Yellow to blue \\
\hline \multirow{3}{*}{ 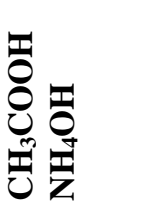 } & Phenolphthalein & $8.83 \pm 0.058$ & Colourless to pink \\
\hline & Ethanol Acanthus pubescens flower extract & $8.10 \pm 0.100$ & Pink to colourless \\
\hline & $\begin{array}{l}\text { Acidified ethanol Acanthus pubescens flower } \\
\text { extract }\end{array}$ & $8.87 \pm 0.115$ & Pink to colourless \\
\hline
\end{tabular}

*Standard Deviation

A comparison of the results of titration of $1 \mathrm{M}$ hydrochloric acid and $1 \mathrm{M}$ ammonium hydroxide solutions (i.e. strong acid versus weak base) using these plant extracts as indicators as presented in Table 3 indicated that the average titre using ethanolic and acidified Acanthus pubescens flower extracts were the same $(11.33 \pm 0.058 \mathrm{~mL})$, while that of methyl red, bromothymol blue and phenolphthalein are $11.20 \pm 0.200,11.30 \pm 0.100$ and $11.40 \pm 0.173$ all in $\mathrm{mL}$ respectively. Hence the end points obtained using the extracts of Acanthus pubescens flower are fairly comparable to the end points obtained using the commercial indicators i.e. methyl red, bromothymol blue and phenolphthalein. The flower extracts of Acanthus pubescens could be used as excellent substitutes to methyl red, bromothymol blue and phenolphthalein for strong acid against weak base titrations.

For weak acid vs. strong base titration, the end point obtained using ethanol and acidified ethanol extracts of Acanthus pubescens flower are in the $10.40 \pm 0.100 \mathrm{~mL}$ to $10.43 \pm 0.058 \mathrm{~mL}$ range which is close to that obtained using phenolphthalein $(10.40 \pm 0.100 \mathrm{~mL})$ but indicates slight statistical deviation from the end point obtained with methyl red $(9.53 \pm 0.058 \mathrm{~mL})$ and bromothymol blue $(9.67 \pm 0.058 \mathrm{~mL})$ in the titrations involving $1 \mathrm{M}$ acetic acid and $1 \mathrm{M}$ sodium hydroxide solutions. These slight differences are attributed to the decrease in dissociation of acetic acid in acidified and pure ethanol. The Acanthus pubescens flower ethanolic and acidified ethanol extracts are therefore good substitutes for phenolphthalein in this type of titration.

For the titration of weak acid with weak base $\left(\mathrm{CH}_{3} \mathrm{COOH}\right.$ vs. $\left.\mathrm{NH}_{4} \mathrm{OH}\right)$, the end point obtained with acidified ethanol extract of Acanthus pubescens flower was $8.87 \pm 0.115 \mathrm{~mL}$ while ethanol extract of Acanthus pubescens flower changed colour at mean titre of $8.10 \pm 0.100 \mathrm{~mL}$. The end point obtained using acidified ethanol extract of Acanthus pubescens 
flower was comparable to the end points obtained using phenolphthalein $(8.83 \pm 0.058 \mathrm{~mL})$ and bromothymol blue $(8.77$ $\pm 0.208 \mathrm{~mL})$ but significantly different from the end point obtained with methyl red $(8.07 \pm 0.115 \mathrm{~mL})$ while the end points obtained using ethanol Acanthus pubescens flower extract was closest to the end point obtained with methyl red but it shows significant deviation from the end point obtained with phenolphthalein in this medium. Hence the acidified ethanol extract of this plant could be used in place of phenolphthalein while the ethanol extract can replace methyl red in weak acid versus weak base tritrations. Variations in titre volumes of the indicators for the weak acid-weak base titrations are due to lack of sharp end points for these combination and complex $\mathrm{pH}$ dependant protonation-deprotonation reactions, as shown in Figure 2, as well as changes in pKa values of the anthocyanin pigments. Mixed indicators are appropriate for such titrations to signal end points at the various $\mathrm{pH}$ values.

The results of this study are similar to the observations reported by various researchers (Jaspreet et al., 2011; Thote et al., 2015; Abbas, 2012; Senathirajah et al., 2017) that did related work on indicators using different parts of plant extracts, but there was a slight difference in the result as compared with that of Nhapi (2016) and Pimpodkar (2014).

\section{Conclusion}

The acid -base indicators used in the chemistry laboratory are very often synthetic which are expensive for the schools to afford for their large number of laboratory sessions, are toxic to students and teachers especially when they produce vapours in the laboratory classes, are pollutants to the school surrounding affecting animal and human health. This study focused on a natural indicator for acid-base titrations which is extracted from Acanthus pubescens flower. Four combinations of acid-base titration were studied: strong acid versus strong base, strong acid versus weak base, weak acid versus strong base, and weak acid versus weak base. The color change of the extracts, $\mathrm{pH}$ ranges and the average end point volumes were determined for each type of acid-base titration. These results were similar to those obtained from three selected synthetic indicators namely: methyl red, bromothymol blue and phenolphthalein. The presence of anthocyanins and flavonoids as active components of plant extract were chemically and spectrophotometrically analyzed. The authors concluded that the natural acid-base indicators prepared from pure and acidified ethanol extracts of Acanthus pubescens flower could be good replacements for synthetic indicators as they are less expensive, available, simple to manage and environmentally benign.

\section{References}

Abbas, S. K. (2012). Study of acid-base indicator property of flowers of Ipomoea biloba. International Current Pharmaceutical Journal, 1(12), 420-422. https://doi.org/10.3329/icpj.v1i12.12452

Abugri, D. A., Apea, O. B., \& Pritchett, G. (2012). Investigation of a simple and cheap source of a natural indicator for acid-base titration: effects of system conditions on natural indicators. Green and Sustainable Chemistry, 2(3), 117-122. https://doi.org/10.4236/gsc.2012.23017

Ahmed, J. K., Salih, H. A., \& Hadi, A. G. (2013). Anthocyanins in red beet juice act as scavengers for heavy metals ions such as lead and cadmium. International Journal of Science and Technology, 2(3), 269-274.

Ekpo, U. A. (2007). Determination of the $\mathrm{pK}$ and transition range of cyanidin as an acid-base indicator. University of Nigeria Research Publications, 1-20.

Etagegnehu, A.,Israel, A., Milkyas, E., \& Fikre, M. (2016). Iridoid glycosides from the root of Acanthus sennii. Journal of Pharmacy and Pharmacognosy Research, 4(6), 231-237.

Gupta, P., Jain, P., \& Jain, P.K. (2013). Dahalia flower sap a natural resource as indicator in acidimetry and alkalimetry. International Journal of Pharmacy and Technology, 4(4), 5038-5045.

Jaspreet, S., Kanika, A., Perminder, N., \& Geeta, D. (2011). Herbal indicators as an upcoming trend in titremetric analysis. International Research Journal of Pharmacy, 2(4), 177-179.

Jeruto, P., Lukhoba, C., Ouma, G., Otieno, D., \& Mutai, C. (2008). An ethnobotanical study of medicinal plants used by the Nandi people in Kenya. Journal of Ethnopharmacology, 116(2), 370-376. https://doi.org/10.1016/j.jep.2007.11.041

Khoddami, A., Wilkes, M. A., \& Roberts, T. H. (2013). Techniques for analysis of plant phenolic compounds. Molecules, 18(2), 2328-2375. https://doi.org/10.3390/molecules18022328

Kolthoff, I. M. (1937). Acid-base indicators, The Macmillan company, New York, 103-236.

Loganathan, V., Devi, K. M., \& Selvakumar, P. (2017). A study of the physico-chemical and phytochemical parameters of leaves of Mallotus rhamnifolius. International Journal of Pharmacognosy and Phytochemical Research, 9(6), 858-863. https://doi.org/10.25258/phyto.v9i6.8191 
Mane, A. N., Koli, D. S., \& Kumbhar, V. B. (2016). Use of combretum indicum flower extract as a natural indicator in acid-base titration. International Journal of Institutional Pharmacy and Life Sciences, 6(3),316-324

Moshi, M. J., Innocent, E., Otieno, J. N., Magadula, J. J., Nondo, R. S. O., Otieno, D. F., ... Mbabazi, P. (2010). Antimicrobial and brine shrimp activity of Acanthus pubescens root extracts. Tanzania Journal of Health Research, 12(2), 155-158. https://doi.org/10.4314/thrb.v12i2.56406

Nhapi, C. T. (2016). Application of Eichhornia crassipes root extract as an acid-base indicator. Degree of Bachelor of Science Honours in Chemical Technology, Midlands State University, 1-82.

Nuryanti, S., Matsjeh, S., Anwar, C., Raharjo, T. J., \& Hamzah, B. (2013). Corolla of roselle (Hibiscus sabdariffa L.) as acid-base indicator. European Journal of Chemistry, 4(1), 20-24. https://doi.org/10.5155/eurjchem.4.1.20-24.620

Obaseki, O. S., Olugbuyiro, J. A., De, D. K., \& Kesinro, O. R. (2017). Analysis of UV spectra of some natural plant dyes applicable in fabrication of grätzel cells. Journal of scientific and engineering research, 4(9), 418-424.

Obouayeba, A. P., Diarrassouba, M., Soumahin, E. F., \& Kouakou, T. H. (2015). Phytochemical analysis, purification and identification of Hibiscus anthocyanins. Journal of Pharmaceutical, Chemical and Biological Sciences, 3(2), 156-168.

Patrakar, R., Gond, N., \& Jadge, D. (2010). Flower extract of Jacaranda acutifolia used as a natural indicator in acid base titration. International journal of Pharmtech Research, 2(3), 1954-1957.

Pimpodkar, N. V., Surve, B. S., \& Bhise, S. H. (2014). Use of Argyreia cuneata flower extract as a natural indicator in acid base titration. Journal of Current Pharma Research,4(2), 1124-1127. https://doi.org/10.33786/JCPR.2014.v04i02.002

Said, M. H. (2017). Analytical chemistry 4. University of Babylon, Iraq, 1-16, http://www.uobabylon.edu.iq/eprints/publication_1_21853_24.pdf

Senathirajah, T., Rasalingam, S., \& Ganeshalingam, S. (2017). Extraction of the cyanidin-3- sophoroside from Hibiscus Rosa-Sinensis: An efficient natural indicator over a wide range of acid-base titrations. Journal of Natural Product and Plant Resources, 7(3), 1-7.

Seswa, F. (2016). Assessment of human activities on the vegetation of tropical rainforest in Kakamega County, Kenya, Master thesis in Kenyatta University.Nairobi (Kenya), 52.

Shah, K. H. (2016). Phytochemical screening and isolation of rutin from Cedrela toona roxb leaves. International Journal of Pharmacy and Biological Sciences, 7(3), 274-287.

Sikolia, S. F., \& Omondi, S. (2017). Phytochemical analysis of some selected plants and families in the university botanic garden Of Maseno, Kenya. IOSR Journal of Pharmacy and Biological Sciences, 12(4), 31-38. https://doi.org/10.9790/3008-1204023138

Singh, S., Bothara, S. B., Singh, S., Patel, R., \& Ughreja, R. (2011). Preliminary pharmaceutical characterization of some flowers as natural indicator: acid-base titration. Pharmacognosy Journal, 3(22), 39-43. https://doi.org/10.5530/pj.2011.22.8

Thote, P., Mandir, G.V., \& Narsingarh (2015). Green chemistry: study of acid-base indicator property of golden beet root. International Journal of research - Granthaalayah, 3(9), 1-6.

Wuletaw, A. A., \& Delele, W. A. (2016). Dye-sensitized solar cells using natural dye as light-harvesting materials extracted from Acanthus sennii chiovenda flower and Euphorbia cotinifolia leaf. Journal of science: Advanced Materials and Devices, 1(4), 488-494. https://doi.org/10.1016/j.jsamd.2016.10.003

\section{Copyrights}

Copyright for this article is retained by the author(s), with first publication rights granted to the journal.

This is an open-access article distributed under the terms and conditions of the Creative Commons Attribution license (http://creativecommons.org/licenses/by/4.0/). 